\title{
Quality of Life in Danish Blood Donors Treated for Superficial Fungal Infections
}

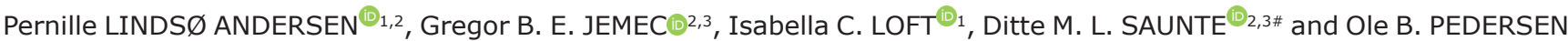 \\ (i) $1,3 \#$ \\ ${ }^{1}$ Department of Clinical Immunology, Naestved Hospital, Naestved, '2Department of Dermatology, Zealand University Hospital Roskilde, \\ Sygehusvej 5, DK-4000 Roskilde, and ${ }^{3}$ Department of Clinical Medicine, Health Sciences Faculty, University of Copenhagen, Denmark. \\ E-mail: pehso@regionsjaelland.dk \\ \#Shared senior authorship. \\ Accepted Nov 29, 2021; Epub ahead of print Nov 29, 2021
}

Superficial fungal infections (SFI) of the skin, nails or hair are treated with topical or systemic antimycotic drugs (1). Physical symptoms, such as itch, pain and hair loss, can lead to impaired quality of life (QoL) in patients with SFI (2). Previous studies on QoL in patients with SFI have either focused exclusively on nail infections (2) or patients treated in hospitals, representing more severe cases of SFI (3-5). The aim of this study was to investigate QoL in individuals treated for SFI compared with those not treated for SFI in a cohort of Danish blood donors.

Blood donors ( $>18$ years of age) participating in the Danish Blood Donor Study (DBDS) (from June 1, 2018 to March 29, 2019) were included in the study. As blood donors are required to be in good health to donate blood, the study cohort had no predisposing conditions for SFI, i.e. immunosuppression and cardiovascular disease. Participants with a history of SFI were identified using a questionnaire item: "Have you had fungal infection in your skin or nails?". To further validate the phenotype, only participants treated by a physician with $>1$ antimycotic agent were considered to be cases. Participants who answered "no" and had no relevant prescription were classed as "controls". Data on antimycotic treatment were obtained from the Danish National Prescription Registry (DNPR) (from January 1, 1995 to June 30, 2018).

\section{MATERIALS, METHODS AND RESULT}

QoL was measured using the Short Form 12 questionnaire, scored in 2 dimensions; the physical component score (PCS) and mental component score (MCS). The PCS includes general health perception, physical functioning, and pain, while the MCS includes mood, social activities, and work ability explained by emotional factors (6). Symptoms of depression were assessed with the validated Major Depression Inventory (MDI) (7) and questionnaire data on previously diagnosed depression. Cohen's Perceived Stress Scale categorized psychological stress into low, moderate, and high stress level. Other covariates, including sex, age, annual income, work status, and highest obtained education level, were obtained through national registers, while smoking and body mass index were obtained through the DBDS questionnaire.

Cumulative prevalence was determined as the proportion with self-reported SFI only, and the proportion of prescription-validated SFI cases. Associations between SFI treatment and demographic factors and lifestyle were investigated with logistic regressions. Linear regressions predicted QoL by SFI were adjusted for age, sex, smoking, BMI, and demographic. Similarly, logistic regressions, adjusted for the aforementioned confounders, assessed associations between stress/depression (outcome) and SFI treatment (predictor). $p$-values $<0.05$ were considered statistically significant and Holm-
Bonferroni corrected for multiple tests. Analyses were performed in RStudio ${ }^{\circ}$ version 1.2.1578 (RStudio ${ }^{\circledR}$, Boston, MA, USA).

The study included 30,334 participants (52.1\% males, $47.9 \%$ females). A total of 7,553 participants reported SFI, corresponding to a cumulative prevalence of $24.9 \%$ ( $95 \%$ confidence interval (95\% CI) $24.4-25.4 \%)$. Of these, 3,466 (11.4\% in total, 95\% CI 11.1-11.8\%) were treated for SFI (Table I). In comparison, 12,406 participants were considered as controls. A total of 2,038/3,466 (58.8\%) received topical agents only, 267/3,466 (7.7\%) received systemic agents only, and 1,161/3,466 (33.5\%) received both. Table $\mathrm{SI}^{1}$ presents cumulative age adjusted prevalence of SFI treatment. SFI treatment was associated with male sex (OR 1.41; 95\% CI $1.30-1.52)$, increase in age per year (OR $1.02 ; 95 \%$ CI $1.02-1.02$ ), increase in BMI (OR 1.03; 95\% CI 1.02-1.04), and education level higher than high-school (OR 1.37; 95\% CI 1.26-1.48).

Treatment for SFI was negatively associated with PCS $(-1.58$ points; 95\% CI $-2.19,-0.99)$ and MCS $(-2.75$ points; 95\% CI $-3.48,-2.02)$ after adjustment. Likewise, participants treated for SFI had an increased risk of higher stress level (OR 1.31; 95\% CI 1.21-1.43) and higher risk of previous depression diagnosis (OR $1.58 ; 95 \%$ CI 1.30-1.91), than control participants (Table I). Effect sizes of relevant confounders of QoL are shown in Tables SII and SIII $^{1}$. Separate data on participants treated for onychomycosis are shown in Table SIV ${ }^{1}$.

\section{DISCUSSION}

Dermatophytosis has been shown to markedly decrease QoL, correlating with the severity and spread of the disease in patients treated in hospital (3-5). Furthermore, patients with SFI may experience psychological distress due to embarrassment, low self-esteem, anxiety, and depression (4). However, these results are of Indian origin, a country with a widespread epidemic of dermatophytosis in up to $37-78 \%$ of the population, often occurring as recalcitrant disease (3). However, our results support that, even in Danish blood donors, with presumably milder disease than subjects in India, SFI, or at least SFI treatment, is associated with QoL impairment (Table I). Furthermore, the current study showed correlations with previous depression and mental stress in participants treated for SFI (Table I). However, these findings may be confounded by SFI treatment as a proxy for other diseases or a general health-seeking behaviour.

Consistent with the literature, treatment for SFI was associated with older age, male sex, and higher BMI (8). Surprisingly, no association was observed between smok-

${ }^{1}$ https://doi.org/10.2340/actadv.v101.749 
Table I. Demographics and outcomes

\begin{tabular}{|c|c|c|c|c|c|c|c|c|c|}
\hline \multirow{2}{*}{$\begin{array}{l}\text { Demographics } \\
\text { SFI }{ }^{\mathrm{a}} / \text { controls }\end{array}$} & \multicolumn{5}{|l|}{ Men } & \multicolumn{4}{|l|}{ Women } \\
\hline & \multicolumn{2}{|l|}{ SFI, $n=2,126$} & \multicolumn{3}{|c|}{ Controls, $n=6,463$} & \multicolumn{2}{|l|}{ SFI, $n=1,340$} & \multicolumn{2}{|c|}{ Controls, $n=5,943$} \\
\hline Median age at inclusion, years (IQR) & \multicolumn{2}{|l|}{$46.0(36.0-54.8)$} & \multicolumn{3}{|c|}{$41.1(29.2-52.2)$} & \multicolumn{2}{|l|}{$43.5(33.1-52.3)$} & \multicolumn{2}{|l|}{$39.1(26.5-51.5)$} \\
\hline Mean BMI (SD) & \multicolumn{2}{|l|}{$26.6(3.8)$} & \multicolumn{3}{|c|}{$26.1(3.8)$} & \multicolumn{2}{|l|}{$26.3(4.9)$} & \multicolumn{2}{|l|}{$25.7(4.6)$} \\
\hline Current smokers, $n(\%)$ & \multicolumn{2}{|c|}{$248(11.7)$} & \multicolumn{3}{|c|}{$910(14.1)$} & \multicolumn{2}{|l|}{$177(13.2)$} & \multicolumn{2}{|l|}{$852(14.3)$} \\
\hline Median yearly income, DKK (IQR) & \multicolumn{2}{|c|}{$439,824(338,823-570,270)$} & \multicolumn{3}{|c|}{$395,587(257,407-522,484)$} & \multicolumn{2}{|c|}{$360,119(248,000-444,808)$} & \multicolumn{2}{|c|}{$329,730(181,797-428,072)$} \\
\hline \multicolumn{10}{|l|}{ Highest education, $n(\%)$} \\
\hline Elementary school & \multicolumn{2}{|l|}{$142(6.8)$} & \multicolumn{3}{|c|}{$681(10.8)$} & \multicolumn{2}{|l|}{$88(6.7)$} & \multicolumn{2}{|l|}{$541(9.3)$} \\
\hline High-school & \multicolumn{2}{|l|}{$964(46.3)$} & \multicolumn{3}{|c|}{$3,177(50.4)$} & $555(42.1)$ & & $2,723(46.8)$ & \\
\hline Short-cycle higher education ( $2-2.5$ years) & $212(10.2)$ & & 550( & $(8.7)$ & & $107(8.1)$ & & $343(5.9)$ & \\
\hline Medium-cycle higher education (3-4 years) & $416(20.0)$ & & 1,058 & $8(16.8)$ & & $408(30.9)$ & & $1,640(28.2)$ & \\
\hline Long-cycle higher education (5-6 years) & $349(16.8)$ & & 835( & $(13.3)$ & & $161(12.2)$ & & $566(9.7)$ & \\
\hline Socioeconomic status, $n(\%)$ & & & & & & & & & \\
\hline Working & $1,879(88.4)$ & & 5,190 & $(80.3)$ & & $1,075(80.2)$ & & $4,271(71.9)$ & \\
\hline $\begin{array}{l}\text { Unemployed or receiver of public economic } \\
\text { support }\end{array}$ & $37(1.8)$ & & 150( & $(2.4)$ & & $38(2.8)$ & & $162(2.7)$ & \\
\hline Students & $158(7.4)$ & & 977( & $(15.1)$ & & $190(14.2)$ & & $1,354(22.8)$ & \\
\hline Retired & $34(1.6)$ & & $86(1$ & & & $27(2.0)$ & & $100(1.7)$ & \\
\hline Other & $18(0.8)$ & & $60(0$ & & & $10(0.7)$ & & $56(0.9)$ & \\
\hline Outcomes & & & & & & & Regressions & & \\
\hline Health-related quality of life & $\begin{array}{l}\text { SFI (all), } \\
n=2,126\end{array}$ & $\begin{array}{l}\text { Controls, } \\
n=6,463\end{array}$ & & $\begin{array}{l}\text { SFI (all), } \\
n=1,340\end{array}$ & Cont & trols, $n=5,943$ & $\begin{array}{l}\text { Change in } \subseteq \\
{[95 \% \mathrm{CI}]}\end{array}$ & SF-12 score (\%) & $p$-value \\
\hline $\begin{array}{l}\text { Physical health (physical component score), } \\
\text { median (IQR) }\end{array}$ & $\begin{array}{l}55.16(52.36- \\
56.81)\end{array}$ & $55.8(53.4$ & $4-56.9)$ & $55.2(52.3-56.8)$ & 55.8 & $3(53.4-57.2)$ & $\begin{array}{l}-1.58[-2.19 \\
(-2.93 \%[-4\end{array}$ & $\begin{array}{l}9,-0.99] \\
4.05 \%,-1.83 \%])\end{array}$ & $<0.001 *$ \\
\hline $\begin{array}{l}\text { Mental health (mental component score), } \\
\text { median (IQR) }\end{array}$ & $54.1(49.0-56.7)$ & 54.6 & $3-56.7)$ & $52.2(45.7-55.3)$ & 52.7 & $7(46.5-55.3)$ & $\begin{array}{l}-2.75[-3.48 \\
(-5.53 \%[-7\end{array}$ & $\begin{array}{l}8,-2.02] \\
7.01 \%,-4.07 \%])\end{array}$ & $<0.001 *$ \\
\hline Stress, $n(\%)$ & & & & & & & OR $[95 \% \mathrm{C}$ & & $p$-value \\
\hline Low & $1,507(72.7)$ & $4,821(76$ & & $818(62.8)$ & 3,86 & $52(66.2)$ & Reference & & \\
\hline Moderate & $563(27.2)$ & $1,496(23$ & & $474(36.4)$ & 1,93 & $39(33.3)$ & $1.31[1.21,1$ & 1.43] & $<0.001 *$ \\
\hline High & $<5(1.1)$ & $20(0.3)$ & & $10(0.1)$ & $29(C$ & $0.4)$ & & & \\
\hline Depression, $n(\%)$ & & & & & & & OR $[95 \% \mathrm{C}$ & & $p$-value \\
\hline $\begin{array}{l}\text { Classification by major depression inventory, } \\
\text { yes }(\%) / \text { no }(\%)\end{array}$ & $\begin{array}{l}<5(<2.0) / 1267 \\
(>98.0)\end{array}$ & $\begin{array}{l}14(0.3) / 3 \\
(99.7)\end{array}$ & 3,994 & $\begin{array}{l}<5(<2.0) / 667 \\
(>98.0)\end{array}$ & $\begin{array}{l}12(0 \\
(99.6\end{array}$ & $(0.4) / 3,146$ & $\mathrm{~N} / \mathrm{A}$ & & \\
\hline Diagnosed by a physician, yes (\%)/no (\%) & $\begin{array}{l}71(5.6) / 1,198 \\
(94.4)\end{array}$ & $\begin{array}{l}198(5.0) / 3 \\
(95.0)\end{array}$ & 13,799 & $\begin{array}{l}98(14.6) / 572 \\
(85.4)\end{array}$ & 256 & $\begin{array}{l}(8.1) / 2,901 \\
9)\end{array}$ & $1.58[1.30,1$ & 1.91] & $<0.001 *$ \\
\hline
\end{tabular}

Percentages are based on received answers, not necessarily the entire cohort.

${ }^{a}$ Treatment for superficial fungal infections (SFI) was defined as $>1$ antimycotic agent of either topical amorolfine, clotrimazole, miconazole, econazole, terbinafine, ciclopirox, or ketoconazole, or systemic griseofulvin or terbinafine. b Adjusted for age, sex, body mass index (BMI), smoking, income, education and socioeconomic status (SES). *Significant after Holm-Bonferroni correction.

IQR: interquartile range ( $25^{\text {th }}$ to $75^{\text {th }}$ percentile); SD: standard deviation; N: number of individuals; DKK: Danish Kroner (100 DKK 13.4 $€$ ); SF-12: Short Form 12 on health-related quality of life; $95 \% \mathrm{CI}$ : $95 \%$ confidence interval; N/A: not applicable due to low sample size; OR: odds ratio.

ing and SFI treatment, even though smoking is generally associated with infections $(9,10)$. Interestingly, higher level of education was positively associated with SFI treatment in the current study. This is in contrast with research suggesting that low socioeconomic status is associated with tinea (1). We speculate that participants with a higher level of education may have increased awareness of their health and a low threshold for seeking medical assistance for SFI.

Different SFIs may affect QoL to various extents. Thus, we added supplementary data on the most common SFI, onychomycosis (Table SIV ${ }^{1}$ ), although these data did not reveal any associations between onychomycosis treatment and mental QoL. The large sample size and valid register data on antimycotic agents prescribed by physicians in the current study qualifies our prevalence estimates and risk factor associations. The study is limited by the absence of mycologically verified cases and data on the use of over-the-counter antimycotics (11). However, the aim of the study was to describe individuals treated for SFI by a physican. As antimycotics are sold at a reduced price when prescribed by a physician, we believe that true cases are likely registered in the DNPR.
In conclusion, treatment for SFI is common, even in a cohort without known predisposing factors. Furthermore, treatment for SFI seems to be associated with impaired QoL, higher level of mental stress, and previous depression, and higher level of education in Danish blood donors.

\section{ACKNOWLEDGEMENTS}

The Danish Blood Donor Study is funded by: The Danish Council for Independent Research - Medical Sciences (grant number 09-069412); The Danish Administrative Regions (http://www. regioner.dk); The A. P. Møller Foundation for the Advancement of Medical Science; The Danish Bio- and Genome Bank (http:// www.regioner.dk/rbgben). None of the funders had any influence on study design, data collection and analysis, decision to publish, or preparation of this manuscript.

Oral and written informed consent was obtained from all participants. The DBDS (1-10-72-95-13) and DBDSII (SJ-740) are approved by the Scientific Ethical Committees in Central Denmark Region and Region Zealand, respectively. The DBDS was approved by the Danish Data Protection Agency (P-2019-99). This study was conducted in accordance with the principles of the Declaration of Helsinki.

PLA and ICL received support from Naestved, Slagelse and Ringsted Hospitals' Research Fund, and PLA received a PhD grant 
from LEO Foundation (grant number LF18002). DMLS participated in advisory board meeting by AbbVie, Janssen, Sanofi, Leo Pharma and received honoraria. DMLS also received speaker's honoraria and/or grants from the following companies: Abbvie, Desitin, Pfizer, Galderma, Novartis and Leo Pharma during the last 5 years. GBJ reports grants from Leo Research Foundation, during the conduct of the study; personal fees from Abbvie, personal fees from Chemocentryx, personal fees from Kymera, personal fees from Leo Pharma, personal fees from Coloplast, grants and personal fees from Novartis, grants and personal fees from UCB, grants and personal fees from Inflarx, grants from Janssen-Cilag, grants from Serono, grants from Regeneron, outside the submitted work. OBP has no conflicts of interests to disclose.

\section{REFERENCES}

1. Havlickova B, Czaika VA, Friedrich M. Epidemiological trends in skin mycoses worldwide. Mycoses 2008; 51: 2-15.

2. Gupta AK, Mays RR. The impact of onychomycosis on quality of life: a systematic review of the available literature. Skin Appendage Disord 2018; 4: 208-216.

3. Mushtaq S, Faizi N, Amin SS, Adil M, Mohtashim M. Impact on quality of life in patients with dermatophytosis. Australas J Dermatol 2020; 61: e184-e188.

4. Narang T, Bhattacharjee R, Singh S, Jha K, Kavita, Mahajan
R, et al. Quality of life and psychological morbidity in patients with superficial cutaneous dermatophytosis. Mycoses 2019; 62: 680-685.

5. Patel NH, Padhiyar JK, Patel AP, Chhebber AS, Patel BR, Patel TD. Psychosocial and financial impact of disease among patients of dermatophytosis, a questionnaire-based observational study. Indian Dermatol Online J 2020; 11: 373-377.

6. Steenstrup T, Pedersen OB, Hjelmborg J, Skytthe A, Kyvik KO. Heritability of health-related quality of life: SF-12 summary scores in a population-based nationwide twin cohort. Twin Res Hum Genet 2013; 16: 670-678.

7. Olsen LR, Jensen DV, Noerholm V, Martiny K, Bech P. The internal and external validity of the Major Depression Inventory in measuring severity of depressive states. Psychol Med 2003; 33: 351-356.

8. Burzykowski T, Molenberghs G, Abeck D, Haneke E, Hay R, Katsambas $A$, et al. High prevalence of foot diseases in Europe: results of the Achilles Project. Mycoses 2003; 46: 496-505.

9. Lu L, Mackay DF, Pell JP. Meta-analysis of the association between cigarette smoking and peripheral arterial disease. Heart 2014; 100: 414-423.

10. Kaspersen KA, Pedersen OB, Petersen MS, Hjalgrim $H$, Rostgaard K, Moller BK, et al. Obesity and risk of infection: results from the Danish Blood Donor Study. Epidemiology 2015; 26: 580-589.

11. Lindso Andersen P, Jemec GB, Pedersen OB, Saunte DM. An increase in use of antifungals for superficial infections in Denmark during 1997-2018. APMIS 2021; 129: 32-34. 